\title{
Colonic and systemic effects of extruded whole-grain sorghum consumption in growing Wistar rats
}

\author{
Emilce E. Llopart ${ }^{1}$, Raúl E. Cian ${ }^{1}$, Muñoz María Elvira López-Oliva ${ }^{2}$, Ángela Zuleta ${ }^{3}$, Adriana Weisstaub ${ }^{3}$ \\ and Silvina R. Drago ${ }^{1 *}$ \\ ${ }^{1}$ Consejo Nacional de Investigaciones Científicas y Técnicas (CONICET), Facultad de Ingeniería Química, Instituto de \\ Tecnología de Alimentos, Universidad Nacional del Litoral, Santiago del Estero 2829, Santa Fe, Argentina \\ ${ }^{2}$ Facultad de Farmacia, Universidad Complutense de Madrid, Plaza de Ramón y Cajal, s/n, 28040 Madrid, Spain \\ ${ }^{3}$ Facultad de Farmacia y Bioquímica, Universidad de Buenos Aires, Junín 956 CABA, Argentina
}

(Submitted 7 February 2017 - Final revision received 22 August 2017 - Accepted 25 August 2017)

\section{Abstract}

Colonic effects of extruded whole-grain sorghum diets were evaluated using a model of growing rats. In all, twenty-four male Wistar rats were fed control (C), extruded white sorghum (EWS) or red sorghum (ERS). Consumption of sorghum diets showed satiety properties, with reduction of caecal $\mathrm{pH}$, and lower activity of $\beta$-glucosidase and $\beta$-glucuronidase enzymes. Decreased copper zinc superoxide dismutase and manganese superoxide dismutase and increased catalase and glutathione peroxidase levels were observed in colonic mucosa. The induction of antioxidant enzymes occurred through the activation of the nuclear factor erythroid 2-related factor 2 protein and its subsequent translocation into the nucleus. ERS was able to decrease the proliferation of proximal mucosa of colon, demonstrating a possible effect against colorectal tumourigenesis. EWS increased proliferation and also apoptosis, ensuring the re-establishment of homoeostasis of the colonic mucosa. No antioxidant systemic effect (serum or hepatic level) was observed. It is likely that despite the extrusion the low bioavailability of the phenolic compounds of sorghum diets caused them to exert mainly acute effects at the colon level. Extruded whole-grain sorghum is a good functional ingredient that might be promising in dietary prevention of intestinal diseases.

Key words: Whole grain: Extruded sorghum: Antioxidant status: Lipid profile: Colon health

Dietary recommendations of the World Strategy for populations ${ }^{(1)}$ recommend the consumption of whole grain (WG). The beneficial effects of WG on health are owing to fibre, micronutrients and phytochemicals present in the outer layer of the grain and germ. Epidemiological studies suggest that the consumption of WG reduces mortality from CVD, which is probably related to its antioxidant (AO) properties ${ }^{(2)}$, as WG is an important source of $\mathrm{AO}^{(3)}$. There has been an increased interest in finding natural $\mathrm{AO}$ from plants to scavenge free radicals to be effective in the treatment of oxidative damage. Polyphenols from WG can protect against reactive $\mathrm{O}_{2}$ species-mediated damage by elevating cellular AO defence, showing increased superoxide dismutase $(\mathrm{Cu} / \mathrm{Zn}$ SOD), glutathione peroxidase (GPx) and catalase (CAT) levels ${ }^{(4)}$. Expression of these AO enzymes is mediated by the nuclear transcription factor (erythroid-derived 2)-like 2, a key factor regulating genes that encode $\mathrm{AO}$ and detoxifying enzymes. WG also have both fermentable and non-fermentable fibre. Consumption of different types and amounts of dietary fibre can influence the production of bacterial enzymes with toxicological significance, such as mucinase, $\beta$-glucosidase and $\beta$-glucuronidase ${ }^{(5,6)}$. Dietary fibre with polyphenols not absorbed in the small intestine reaches the colon and can be fermented, modifying the production of certain microbial metabolites ${ }^{(7)}$ and SCFA, which can significantly increase the biomass, reduce the luminal $\mathrm{pH}$, change the composition of flora and modify the gastrointestinal epithelial kinetic pattern ${ }^{(8)}$.

Sorghum is a good source of phytochemical compounds and fibre that have been associated with $\mathrm{AO}$, anti-inflammatory and antiproliferative capacities ${ }^{(9)}$. The $\mathrm{AO}$ activities of whole-grain sorghum are higher than those reported in other cereals, such as rice, wheat and oat ${ }^{(10)}$, which suggests that sorghum is a good source of natural AO. Sorghum grains can contain substantial levels of a wide range of phenolic compounds, mostly flavonoids, and only some varieties with pigmented testa have condensed tannins $^{(11)}$. Thus, different varieties of sorghum can be roughly divided into two categories: tannin-free sorghums, such as white or red sorghum, and tannin sorghums, such as

Abbreviations: AO, antioxidant; C, control diet; CAT, catalase; ERS, extruded red sorghum diet; EWS, extruded white sorghum diet; GPx, glutathione peroxidase; GR, glutathione reductase; PCNA, proliferating cell nuclear antigen; sIgA, secretory IgA; SOD, superoxide dismutase; TUNEL, terminal deoxynucleotidyl transferase dUTP nick end labelling; WG, whole grain.

* Corresponding author: S. R. Drago, email sdrago@fiq.unl.edu.ar 
brown sorghum. Phenolic acids are mainly found in pericarp, testa, aleurone layer and endosperm ${ }^{(12)}$. Free phenolics are found in the outer layers (testa, pericarp and aleurone), whereas bound ones are associated with the cell wall ${ }^{(12-14)}$. Phenolic compounds could be negative in terms of reducing starch, protein and mineral digestibility ${ }^{(15)}$. However, recently, phenolic compounds have gained increased interest because of their AO activity. The most abundant phenols in sorghum are caffeic acid, coumaric, ferulic and sinapic ${ }^{(13,16)}$. The most common anthocyanins in sorghums are the 3-deoxyanthocyanidins, which include orange luteolinidin and yellow $\operatorname{apigeninidin}^{(13,16)}$. On the other hand, sorghum has been known to be a slowly digestible cereal. Bran from black and brown sorghum is known to alter rat faecal SCFA concentrations, which suggests possible changes in the intestinal microbiota and epithelial barrier integrity ${ }^{(17,18)}$. Furthermore, secondary sorghum metabolites from polyphenols are reported to modify differentially luminal bacterial populations and induce systemic effects in vitro and in animal pathological models ${ }^{(19)}$. Thus, because of its low starch digestibility, high polyphenolic levels and AO capacity, WG sorghum has been recognised for the development of health functional foods for chronic disease risk protection.

Processing and cooking conditions do influence sorghum nutrient bioavailability. Extrusion is a high-temperature - shorttime process used widely in the production of a variety of foods such as snack, ready-to-eat cereals, textured vegetable protein, confectioneries and pet foods. It has been shown that extrusion of WG sorghum can lead to enhanced mineral bioavailability and protein digestibility ${ }^{(20)}$. Results of recent studies indicated that the extrusion of sorghum improves the bioavailability of catechins, total phenolics and cinnamic acid ${ }^{(21)}$, which positively affected in vitro $\mathrm{AO}$ and anti-inflammatory capacity ${ }^{(22)}$. Thus, extruded sorghum could be considered as a viable commercial source of $\mathrm{AO}$ and be incorporated as a functional food ingredient. Currently, direct proof of health-enhancing effects of sorghum is lacking as most studies have been carried out on the grains or grain extracts, and not extruded grain itself, and also little research works have been performed in vivo. Currently, little information about the effects of consumption of extruded sorghum on the lipid profile, the AO activity and its impact on the gastrointestinal tract (GIT) is available.

The aim of this study was to evaluate the effect of consumption of white and red whole-grain sorghum precooked by extrusion on systemic, hepatic and colonic oxidative status using a growing Wistar rat model. In addition, its impact on modification in the crypt population of the colonic mucosa has been evaluated.

\section{Methods}

\section{Raw materials and ingredients}

Two commercial sorghum (Sorghum spp) hybrids, white and red, were evaluated. They were free of condensed tannins according to discolouring chlorine test. Grains were ground in a roll mill (Buhler MiagBUA AG) according to a milling diagram, which allows obtaining whole-grain grits with adequate particle size for extrusion (between 1920 and $420 \mu \mathrm{m}$ ), with $<1 \%$ fine fraction (below $420 \mu \mathrm{m}$ ).

Extrusion was carried out using a 20 DN Brabender singlescrew extruder at the following conditions: 4:1 screw compression ratio, $3 \times 20 \mathrm{~mm}$ (diameter-length) die and $150 \mathrm{rpm}$ screw speed, $182^{\circ} \mathrm{C}$ temperature and $14 \mathrm{~g}$ water $/ 100 \mathrm{~g}$ grits moisture.

\section{Animals and diets}

In all, twenty-four male Wistar rats (43.0 (SEM 4.5) g) were obtained from the Animal Service Laboratory, Facultad de Farmacia y Bioquímica, Universidad de Buenos Aires. Throughout the experiment, animals were allowed free access to deionised water and food, and were housed in individual stainless steel cages in a temperature $\left(21 \pm 1^{\circ} \mathrm{C}\right)$ - and humidity $(60 \pm 10 \%)$-controlled room with a $12 \mathrm{~h}$ light-12 $\mathrm{h}$ dark cycle. They were fed the following diets ( $n$ 8/group) during a 60-d period (Table 1 ):

(1) control group (C): in this group, rats were fed a semisynthetic diet prepared according to the American Institute of Nutrition Diet (AIN 93) having $5 \mathrm{~g}$ of cellulose/100 $\mathrm{g}$ diet;

(2) extruded white sorghum group (EWS): in this group, rats were fed the AIN 93 containing $5 \mathrm{~g}$ of fibre per $100 \mathrm{~g}$ of diet from extruded whole-grain white sorghum; and

(3) extruded red sorghum group (ERS): in this group, rats were fed the AIN 93 containing $5 \mathrm{~g}$ of fibre per $100 \mathrm{~g}$ of diet from extruded whole-grain red sorghum.

The analysis of the diets confirmed that they were isoenergetic and supplied a similar amount of macronutrients. The combination of nutrients used in this animal study could reasonably be expected to be achieved in the human population.

This study was carried out in accordance with the National Institute of Health Guide for the Care and Use of Laboratory Animals and approved by the Committee of Health Guide for the Care and Use of Laboratory Animals of the Facultad de Bioquímica y Farmacia, Universidad de Buenos Aires.

\section{Sampling procedures}

Body weights (BW) were recorded once a week and food intakes every $3 \mathrm{~d}$ throughout the experience. Total intakes were

Table 1. Composition of control (C), extruded white sorghum (EWS) and extruded red sorghum (ERS) diets

\begin{tabular}{|c|c|c|c|}
\hline Ingredients (g/kg diet) & C & EWS & ERS \\
\hline Casein & $200 \cdot 0$ & $134 \cdot 6$ & $128 \cdot 2$ \\
\hline Mineral mix (AIN-93M-MX) & $35 \cdot 0$ & 34.0 & 34.0 \\
\hline Vitamin mix (AIN-93-VX) & $10 \cdot 0$ & $10 \cdot 0$ & $10 \cdot 0$ \\
\hline L-Cystine & $3 \cdot 0$ & 3.0 & $3 \cdot 0$ \\
\hline Vitamin A & 1.0 & 1.0 & 1.0 \\
\hline Soyabean oil & $69 \cdot 0$ & 63.5 & $64 \cdot 6$ \\
\hline Choline bitartrate & 71.0 & 71.0 & 71.0 \\
\hline Cellulose & $50 \cdot 0$ & - & - \\
\hline Flour extruded white sorghum & - & $553 \cdot 1$ & - \\
\hline Flour extruded red sorghum & & - & 574.7 \\
\hline Maize dextrine & 624.9 & $193 \cdot 7$ & $177 \cdot 4$ \\
\hline \multicolumn{4}{|l|}{ Phenolic compounds } \\
\hline Free phenolic compounds (mg GA/kg diet) & - & 394.5 & $628 \cdot 3$ \\
\hline Bound phenolic compounds (mg GA/kg diet) & - & $2246 \cdot 1$ & 2423.9 \\
\hline
\end{tabular}

GA, gallic acid. 
calculated. Feed efficiency of diets was determined as the relationship between weight gained by the animal and food consumed - that is weight gain/food intake.

At the end of the experience, rats were anaesthetised with an intraperitoneal injection of $0.1 \mathrm{mg} / 100 \mathrm{~g} \mathrm{BW}$ of ketamine hydrochloride, with $0.1 \mathrm{mg} / 100 \mathrm{~g}$ BW of acepromazine maleate. An abdominal incision was made; blood was withdrawn from the abdominal aorta and centrifuged at 3000-3500 rpm for $20 \mathrm{~min}$ at $4^{\circ} \mathrm{C}$. Serum samples were stored at $-80^{\circ} \mathrm{C}$ and examined within the following $3 \mathrm{~d}$. The liver was excised, weighed, divided in small portions and stored at $-80^{\circ} \mathrm{C}$ for analysis. The caecum was removed and weighed (Mettler Toledo). Caecal content was collected and weighed. After measuring its $\mathrm{pH}$ with a $\mathrm{pH}$-metre (IQ Scientific Instruments), it was diluted $1 / 4$ with PBS buffer $(0.01 \mathrm{~mol} / 1, \mathrm{pH} 7 \cdot 3)$, vortexed and centrifuged at $3000 \mathrm{~g}$ for $20 \mathrm{~min}$. Caecal enzymes were analysed in these samples. The activities of selected bacterial enzymes ( $\beta$-glucosidase and $\beta$-glucuronidase) released into the caecal environment were measured according to the rates of $p$ - and $o$-nitrophenol release from their nitrophenylglucosides ${ }^{(23)}$. Protease inhibitor (P8340; Sigma) was added to an aliquot of this supernatant for further analysis of secretory $\operatorname{IgA}$ (sIgA) using kit. All samples were stored in a freezer at $-80^{\circ} \mathrm{C}$ for later analysis. The colon section was dissected. Sections $(2 \mathrm{~cm})$ of colon (proximal and distal) were routinely processed and paraffin embedded. Sections were cut, stained with haematoxylin-eosin (H\&E) and processed for immunohistochemical staining

\section{Analytical methods}

TAG and cholesterol. Pieces of $250 \mathrm{mg}$ of liver were extracted with chloroform-methanol (2:1) mixture ${ }^{(24)}$. Aliquots were evaporated and cholesterol and TAG were analysed using enzymatic methods (commercial kits: ColestatEnzimático and TAG Color GPO/PAP ascorbic acid; Wiener Lab, respectively). Serum cholesterol and TAG were determined using the kits mentioned before.

Proteins and polyphenols. Protein content was determined according to the method of Lowry et al. ${ }^{(25)}$ using bovine serum albumin as standard (A7906; Sigma Aldrich).

A double extraction was used to extract free (FPC) and bound phenolic compounds (BPC) from sorghum diets ${ }^{(26)}$. Then, phenolics were determined by the Folin-Ciocalteu ${ }^{(27)}$ method using gallic acid (GA) as standard. Total phenolic compounds (TPC) was calculated as the sum of FPC and BPC.

Thiobarbituric acid reactive substances assay. The assay proposed by Buege \& Aust ${ }^{(28)}$ with some modifications was performed to measure thiobarbituric acid (TBA) reactive substances in serum and liver as estimation of lipid peroxidation. In brief, $0.5 \mathrm{~g}$ of liver was homogenised with $5 \mathrm{ml}$ of $30 \mathrm{mmol} / \mathrm{l}$ phosphate buffer ( $\mathrm{pH}$ 7.4) using a homogeniser (PRO250Homogenizer; PRO Scientific). An aliquot of liver homogenate was combined with BHT in ethanol $(0.4 \mathrm{~g} / \mathrm{l})$ and TCA $(200 \mathrm{~g} / \mathrm{l})$ and the mixture was centrifuged for $10 \mathrm{~min}$ at $5000 \mathrm{~g}$. The supernatant was combined in a 1:1 ratio with TBA $(7 \mathrm{~g} / \mathrm{l})$ and the mixture was heated at $100^{\circ} \mathrm{C}$ for $1 \mathrm{~h}$. The absorbance was measured at $535 \mathrm{~nm}$ in the spectrophotometer (Genesys 5; Milton Roy). The results were expressed as malondialdehyde equivalent (MDA eq) (nmol/100 g protein) using MDA molar extinction coefficient $\left(1.56 \times 10^{5}\right.$ litres $/ \mathrm{mol}$ per $\left.\mathrm{cm}\right)$. The same method was used for serum and the results were expressed as MDA eq (nmol/g protein).

Catalase activity. Hepatic CAT was analysed according to Aebi ${ }^{(29)}$. In brief, $0.5 \mathrm{~g}$ of liver was homogenised with $5 \mathrm{ml}$ of $50 \mathrm{mmol} / \mathrm{l}$ phosphate buffer $(\mathrm{pH} \mathrm{7-7.4)}$ ) and centrifuged for $5 \mathrm{~min}$ at $8000 \mathrm{~g}$. Aliquots of the supernatant were diluted $1 / 400$ with phosphate buffer, added with $30 \mathrm{mmol} / 1 \mathrm{H}_{2} \mathrm{O}_{2}$ solution and shaken vigorously. The decrease in absorbance at $240 \mathrm{~nm}$ during $1 \mathrm{~min}$ was measured using the spectrophotometer. CAT activity was calculated using the slope of the absorbance $v$. time (s) curve in a logarithmic scale (log 10). Results were expressed as $\mu \mathrm{mol} / \mathrm{s}$ per g protein using $\mathrm{H}_{2} \mathrm{O}_{2}$ molar extinction coefficient $(0.0394$ litres $/ \mathrm{mmol}$ per $\mathrm{cm})$.

Glutathione reductase and glutathione peroxidase. Glutathione reductase (GR) activity was analysed according to Horn $^{(30)}$. A piece of liver was mixed with $30 \mathrm{mmol} / 1$ phosphate buffer (pH 7.4) with $1 \mathrm{mmol} / \mathrm{l}$ EDTA and $4 \mathrm{mmol} / \mathrm{l}$ dithiothreitol, homogenised on ice and centrifuged for $5 \mathrm{~min}$ at $10000 \mathrm{~g}$ (Z160M; Hermle). An aliquot of liver homogenate was added with $\mathrm{pH} 7.6$ phosphate buffer $\left(100 \mathrm{mmol} / 1 \mathrm{KH}_{2} \mathrm{PO}_{4}, 3.4 \mathrm{mmol} / 1\right.$ EDTA), $30 \mathrm{mmol} / 1 \mathrm{GSSG}$ and $0.8 \mathrm{mmol} / 1 \mathrm{NADPH}$. The reduction of GSSG to GSH by GR activity was measured every $30 \mathrm{~s}$ during $5 \mathrm{~min}$ in a plate reader at $340 \mathrm{~nm}$ (UVM 340; ASYS Hitech). Results were expressed as nmol NADPH/per min per mg protein using the slope of the Absorbance $v$. time (s) curve, NADPH molar extinction coefficient $(3.732 \mathrm{nmol} / \mathrm{ml}), 0.6 \mathrm{~cm}$ length of multi-well plate, $190 \mu$ final reaction volume and protein content of liver homogenate.

Liver GPx activity was measured according to Paglia \& Valentine $^{(31)}$ with some modifications. An aliquot of the same liver homogenate obtained for GR was diluted (1/100) and mixed with phosphate buffer, $\mathrm{pH} 7.0\left(0.0828 \mathrm{~mol} / 1 \mathrm{KH}_{2} \mathrm{PO}_{4}\right.$, $0.0083 \mathrm{~mol} / 1 \mathrm{EDTA}), 0.0028 \mathrm{~mol} / \mathrm{l} \mathrm{NADPH}, \mathrm{GR}(451 \mathrm{U} / \mathrm{ml})$, $0.075 \mathrm{~mol} / 1 \mathrm{NaN}_{3}$ and $0.05 \mathrm{~mol} / 1 \mathrm{GSH}$. The mixture was equilibrated during $5 \mathrm{~min}$ at $20^{\circ} \mathrm{C}$ and the reaction begins with the addition of $0.0007 \mathrm{~mol} / 1 \mathrm{H}_{2} \mathrm{O}_{2}$. The absorbance was measured every $30 \mathrm{~s}$ during $5 \mathrm{~min}$ at $340 \mathrm{~nm}$. The activity was calculated using the slope of absorbance $v$. time (s) curve, NADPH molar extinction coefficient $(4.354 \mu \mathrm{mol} / \mathrm{l}), 0 \cdot 7-\mathrm{cm}$ length of multi-well plate, $200 \mu$ final reaction volume and protein content of liver homogenate. Results were expressed as nmol NADPH/min per mg protein.

GSSG and GSH. Liver GSSG and GSH contents were determined by the fluorometric method of Hissin \& Hilf $^{(32)}$ with modifications. A portion of liver was mixed with phosphate buffer, pH $8\left(0.1 \mathrm{~mol} / 1 \mathrm{Na}_{2} \mathrm{HPO}_{4}, 0.005 \mathrm{~mol} / \mathrm{l}\right.$ EDTA $)$, and an aliquot of $25 \mathrm{~g} / 100 \mathrm{ml} \mathrm{HPO}_{3}$ solution, homogenised on ice and centrifuged at $10000 \mathrm{~g}$ for $10 \mathrm{~min}$. For GSSG assay, an aliquot of the supernatant was mixed with $0.04 \mathrm{ml}$ of $\mathrm{N}$-ethylmaleimide and incubated during $20 \mathrm{~min}$ at room temperature. To this 
mixture, $0 \cdot 1 \mathrm{~mol} / 1 \mathrm{NaOH}$ was added, shaken and an aliquot was used for reacting with $1 \mathrm{mg} / \mathrm{ml}$ O-phthaldialdehyde. After $15 \mathrm{~min}$, the fluorescence at $420 \mathrm{~nm}$ was determined (excitation at $350 \mathrm{~nm}$ ) using a fluorescence spectrophotometer (F2000; Hitachi). For GSH assay, an aliquot of the supernatant, phosphate buffer and $1 \mathrm{mg} / \mathrm{ml} \mathrm{O}$-phthaldialdehyde were incubated during $15 \mathrm{~min}$ at room temperature, and fluorescence was determined as mentioned above. GSSG and GSH contents were expressed as $\mu \mathrm{g} / \mathrm{g}$ of liver.

Assessment of apoptosis. Apoptotic cells in colonic sections were detected using terminal deoxynucleotidyl transferase dUTP nick end labelling (TUNEL) procedure ${ }^{(33)}$. In brief, colonic sections after deparaffinisation and rehydration were permeabilised with proteinase $\mathrm{K}(20 \mu \mathrm{g} / \mathrm{ml})$ for $15 \mathrm{~min}$ at $37^{\circ} \mathrm{C}$. Thereafter, the sections were quenched of endogenous peroxidase activity using 3\% hydrogen peroxide for $10 \mathrm{~min}$. After thorough washing with PBS, the sections were incubated with equilibration buffer for $10 \mathrm{~min}$ and then terminal deoxynucleotidyl transferase reaction mixture was added to the sections, except for the negative control, and incubated at $37^{\circ} \mathrm{C}$ for $1 \mathrm{~h}$. The reaction was stopped by immersing the sections in saline-sodium citrate buffer for $15 \mathrm{~min}$. The incorporated biotinylated nucleotides were detected by streptavidin-horseradish peroxidase (HRP) (1:500) for $30 \mathrm{~min}$ at room temperature, and after repeated washings sections were incubated with diaminobenzidine (DAB) until colour development (5-10 min). The sections were then mounted after dehydration and counterstained with methyl green. The TUNEL labelling index (LI) (\%) was calculated as the number of apoptotic cells $\times 100 /$ total number of cells per crypt column height. For the quantification of the TUNEL LI, at least fifty perpendicular well-oriented crypts were examined and counted for each animal at 400x magnification. These studies were performed using a Leica DM LB2 microscope and a digital Leica DFC 320 camera (Leica).

Immunohistochemical staining. Before immunostaining, the sections were deparaffinised, rehydrated and then treated in 3\% hydrogen peroxide in methanol to inhibit peroxidase activity. They were then boiled in a microwave oven in $0.01 \mathrm{~m}$ sodium citrate buffer ( $\mathrm{pH} \mathrm{6.0)} \mathrm{for} 20 \mathrm{~min}$. To avoid background staining, blocking serum was derived from the same species in which the secondary antibody had been raised. After that, the sections were incubated with the following primary antibodies overnight at $4^{\circ} \mathrm{C}$ : mouse monoclonal anti-proliferating cell nuclear antigen (PCNA; PC-10) (1:50; Lab Vision Corporation and BionovaCientífica SL), rabbit polyclonal anti-cyclo-oxygenase 2 (COX-2) (1:200), rabbit polyclonal anti-inducible nitric oxide synthase (iNOS), rabbit polyclonal anti-Cu, Zn SOD (1:200), rabbit polyclonal anti-Mn SOD (1/200), anti-GPX-1 (1:200), anti-GR (1:200), anti-CAT (1:200) and anti-Nrf-2 (1/50) (Santa Cruz Biotechnology). After washing with PBS, the sections were covered for $30 \mathrm{~min}$ at room temperature with biotinylated goat anti-mouse or goat anti-rabbit (1:400) as secondary antibodies (Santa Cruz Biotechnology). Immunochemical staining was performed for 30 min using streptavidin-biotin-conjugated HRP (Sigma Aldrich) and visualised by incubation with 3, 3'-DAB
(Sigma Aldrich) for $10 \mathrm{~min}$ at room temperature. The sections were counterstained with Harris's haematoxylin, dehydrated and mounted. Brown colour indicates specific protein immunostaining and light blue colour indicates nuclear haematoxylin staining. Positive and negative controls were used during the optimisation of the methods.

For quantification of the PCNA LI \%, at least 20 perpendicular well-oriented crypts were examined in each animal under light microscopy at $400 \times$ magnification. LI was calculated as the number of positive nuclei $\times 100 /$ total number of cells per crypt column height.

The staining intensity of epithelial COX-2, iNOS, SOD, CAT, $G R$ and GPX expression was evaluated according to a semiquantitative immuno-histochemical scoring system as follows: score 0-4: 0, none; 1 , equivocal; 2 , low; 3 , moderate; 4 and above, intense. The number of nuclear $\mathrm{Nrf}$-2-positive cells was quantified by a percentage score with grading between 0 and 4 : 0 , no nuclear staining; $1,1-10 \% ; 2,10-30 \%$; 3, 30-60\%; and 4, 60-100\% positive cells. An additional evaluation was performed in which the stained cells were attributed either to the basal, the middle or the luminal crypt compartments.

The crypt length was measured from H\&E slices and was determined as a distance $(\mu \mathrm{m})$ between the basal side of the lamina epithelialis at the bottom of the crypt and the apical side of the lamina epithelialis at the top of the crypt. Only crypts with an open longitudinal crypt axis were analysed.

\section{Data analysis}

Data were presented as the arithmetic means with their standard errors for each treatment group ( $n$ 8). One-way ANOVA was performed and the statistical differences among samples were determined using least significant difference test. Significance was accepted at $P<0 \cdot 05$.

The data obtained of the semi-quantitative immunohistochemical staining were comparatively analysed using the Kruskal-Wallis test. Multiple comparisons were made through the decomposition of the interaction by applying Tukey's test. The level of significance was set to $5 \%(P<0.05)$ on all tests. Results were expressed as means with their standard errors. All statistical analyses were performed with SPSS 17.1 for Windows (SPSS).

\section{Results and discussion}

\section{Effects of sorghum diets on food intake and weight gain}

Animals fed EWS and ERS diets had lower total intakes than C diet (C: $1115 \cdot 62^{\mathrm{b}}$ (SEM 16.62), EWS: $931.35^{\mathrm{a}}$ (SEM 31.42) and ERS: $985.71^{\mathrm{a}}$ (SEM 23.31$) \mathrm{g} / 60 \mathrm{~d}(P=0.0030)$ ), probably because of the effect on satiety of WG fibre, resulting in less body weight gain (BWG) along $60 \mathrm{~d}\left(310 \cdot 69^{\mathrm{b}}\right.$ (SEM 4.78), 279.49 ${ }^{\mathrm{a}}$ (SEM 7.30) and $279 \cdot 70^{\mathrm{a}}$ (SEM 6.17) g/60 d for C, EWS and ERS, respectively $(P=0.0557))$. However, efficiency did not differ among diets

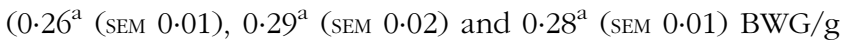
diet for $\mathrm{C}$, EWS and ERS, respectively $(P=0 \cdot 2247))$. Similar results were observed in the previous study using the same model of growing rats fed extruded WG maize ${ }^{(34)}$. Sorghum WG has been proposed as a promising novel ingredient in foods targeting satiety as an adjunct for weight control ${ }^{(15)}$. 


\section{Effect of sorghum diets on caecum}

The consumption of sorghum diets reduced caecal $\mathrm{pH}$ compared with $\mathrm{C}$ diet containing cellulose, which resists fermentation (Table 2). In addition, animals fed extruded WG $\operatorname{corn}^{(34)}$ or WG flours of different wheat varieties ${ }^{(35)}$ or WG wheat bread $^{(36)}$ decreased caecal $\mathrm{pH}$. The caecal fermentation of extruded sorghum may generate great quantities of SCFA and cause lowering of intraluminal colonic $\mathrm{pH}$, which are considered beneficial for intestinal health, because they promote positive microbiota proliferation and decrease the growth of pathogenic bacteria species ${ }^{(37-39)}$. Sorghum diets also supply polyphenols. Total polyphenol content of diets was $2640.6 \mathrm{mg}$ $\mathrm{GA} / \mathrm{kg}$ diet for EWS and $3052.2 \mathrm{mg}$ GA/ $\mathrm{kg}$ diet for ERS, respectively. It has also been proposed that a high concentration of phenols in caecum could exert local beneficial effects within the $\mathrm{GIT}^{(40)}$. However, only the consumption of ERS diet increased SIgA, which could imply a favourable effect on the intestinal barrier and its immune function, whereas EWS decreased sIgA with respect to $C$ (Table 2). The dual effects of EWS (decreased) and ERS (increased) diets on IgA levels could be related to caecal $\mathrm{pH}$ values, SCFA concentrations and/or changes in the microbiota. In this work, the causal relation between an elevation or decrease of caecal IgA concentrations and lowered caecal $\mathrm{pH}$ values found in rats fed sorghum diets is still unclear. Further investigations are needed to elucidate the relationship between the effects of sorghum diets on the caecal IgA secretion. In addition, it was reported that diets containing 15\% sugar beet crude fibre significantly increased SIgA in rats ${ }^{(41)}$.

There were no differences in caecal mucinase activity among diets (Table 2 ). Shiau \& Chang $^{(41)}$ reported that only $15 \%$ guar gum diet reduced mucinase in rats with respect to diets free of fibre, or with 5 or $15 \%$ pectin, carrageenan or cellulose. Rats fed WG sorghum diets decrease the activity of bacterial $\beta$-glucosidase relative to $\mathrm{C}$ (Table 2 ). In addition, Zdunczyk et al. ${ }^{(42)}$ reported a decreased $\beta$-glucosidase activity in turkeys fed ground WG wheat in relation to a diet without WG. Similarly, $\beta$-glucuronidase was significantly reduced with sorghum diets, even more with ERS (Table 2). This enzyme is characteristic of harmful bacteria species, and it has deconjugative properties that support the transformation of xenobiotics into more toxic substances. Shiau \& Chang ${ }^{(41)}$ reported lower activity of this enzyme in the case of rats fed $15 \%$ pectin diets. The inclusion of extruded WG sorghum in the diet can be assumed to selectively modulate the composition of the microbiota and thus decrease bacterial enzymatic activity. $\beta$-Glucosidase and $\beta$-glucuronidase transform pre-carcinogens to carcinogens. Therefore, a decrease in the activity of these enzymes could play an important role in colon carcinogenesis prevention ${ }^{(43,44)}$. Our results indicate that the differential changes observed in caecal $\mathrm{pH}$, sIgA, $\beta$-glucuronidase and $\beta$-glucosidase activities may depend on the nature of the sorghum consumed and different content of free and bound phenolics of each. In this regard, ERS exerted a stronger positive impact on caecal fermentation.

\section{Effect of sorghum diets on colon mucosae}

Antioxidant status. The GIT is a major site for generation of pro-oxidants, whose production is primarily because of the presence of microbiota, food ingredients and interactions between immune cells. To investigate the effect of extruded sorghum diets on the colonic AO system, we examined the immunolocalisation of SOD (Mn SOD and Cu,Zn SOD), CAT, GPx and GR enzymes in proximal and distal mucosa by immunohistochemistry assay (Table 3 and online Supplementary material). The balance of the activity and expression of these enzymes may be critical in oxidative defence of colon. We demonstrated that both sorghum diets induced similar modulation on colonic AO system, showing the highest impact on distal mucosa. The expression of $\mathrm{Cu}, \mathrm{Zn}$ SOD was significantly reduced in sorghum-fed rats compared with those of $\mathrm{C}$ rats $(P<0.0001)$ (Table 3), although only EWS diet showed significant decreases in $M n S O D$ immunoreactivity score in both colonic areas (proximal: $92 \%$; distal $80 \%$; $P<0 \cdot 0001$ ). In distal mucosa, CAT and GPx protein expression levels were significantly increased compared with C (CAT EWS: 93\%, ERS: $120 \%$; GPx EWS: $142 \%$, ERS: $42 \%$ ), resulting in a reduction in the SOD:CAT and SOD:GPX ratios, which may yield a system that can eliminate $\mathrm{H}_{2} \mathrm{O}_{2}$ in a higher rate than it is formed. The balance between the AO enzymes demonstrated a better state of AO protection in distal colon of sorghum-fed rats. This is in agreement with Dani et al. $^{(45)}$ and López-Oliva ${ }^{(46)}$, who reported reduced SOD:CAT and SOD:GPx ratio in the liver of Wistar rats fed purple grape juice or colon of rats fed GADF, respectively, indicating an enhancement of the AO capacity.

High increases of $G R$ expression compared with the $\mathrm{C}$ were found in all animals fed sorghum diets (proximal colon

Table 2. Caecal content (CC), CC PH, caecal polyphenols, reducing power, secretory lgA (slgA), mucinase, $\beta$-glucosidase and $\beta$-glucuronidase activity

(Mean values with their standard errors; $n$ 8/group)

\begin{tabular}{|c|c|c|c|c|c|c|c|}
\hline \multirow[t]{2}{*}{ Diets... } & \multicolumn{2}{|c|}{$\mathrm{C}$} & \multicolumn{2}{|c|}{ EWS } & \multicolumn{2}{|c|}{ ERS } & \multirow[b]{2}{*}{$P$} \\
\hline & Mean & SEM & Mean & SEM & Mean & SEM & \\
\hline Caecal content $\mathrm{pH}$ & $7 \cdot 28^{\mathrm{C}}$ & 0.04 & $6 \cdot 84^{\mathrm{b}}$ & 0.09 & $6 \cdot 56^{a}$ & 0.11 & 0.0051 \\
\hline $\operatorname{slg} A(\mu g / g C C)$ & $11.55^{\mathrm{b}}$ & 2.32 & $1.01^{a}$ & 0.27 & $19.52^{C}$ & $2 \cdot 30$ & 0.0000 \\
\hline Mucinase ( $\mu \mathrm{mol}$ glucose/g CC per h) & $100 \cdot 87^{\mathrm{a}}$ & 3.49 & $97 \cdot 35^{\mathrm{a}}$ & $2 \cdot 63$ & $97 \cdot 00^{\mathrm{a}}$ & $2 \cdot 12$ & 0.7063 \\
\hline$\beta$-Glucosidase ( $\mu$ mol $p$-nitrophenol/g CC per h) & $3.61^{\mathrm{b}}$ & 0.04 & $2 \cdot 77^{\mathrm{a}}$ & 0.21 & $2 \cdot 37^{\mathrm{a}}$ & 0.14 & 0.0407 \\
\hline$\beta$-Glucuronidase ( $\mu \mathrm{mol} p$-nitrophenol/g CC per $\mathrm{h}$ ) & $3.48^{\mathrm{c}}$ & 0.03 & $1.45^{\mathrm{b}}$ & 0.05 & $1.29^{\mathrm{a}}$ & 0.04 & 0.0000 \\
\hline
\end{tabular}

C, control lot; EWS, extruded white sorghum lot; ERS, extruded red sorghum lot.

a,b,c Mean values with unlike superscript letters were significantly different between samples analysed by the least significant difference test $(P<0.05)$. 
Table 3. Copper zinc superoxide dismutase (SOD), manganese SOD, catalase (CAT), glutathione reductase (GR), glutathione peroxidase (GPx), nuclear transcription factor (erythroid-derived 2)-like 2 (Nrf-2), cyclo-oxygenase 2 (COX-2), inducible nitric oxide synthase (iNOS), in proximal and distal colon of rats fed control (C), extruded white sorghum (EWS) and extruded red sorghum (ERS) (Mean values with their standard errors; $n$ 8/group)

\begin{tabular}{|c|c|c|c|c|c|c|c|c|c|c|c|c|c|}
\hline & \multicolumn{2}{|c|}{ C proximal } & \multicolumn{2}{|c|}{ EWS proximal } & \multicolumn{2}{|c|}{ ERS proximal } & \multicolumn{2}{|c|}{ C distal } & \multicolumn{2}{|c|}{ EWS distal } & \multicolumn{2}{|c|}{ ERS distal } & \multirow[b]{2}{*}{$P$} \\
\hline & Mean & SEM & Mean & SEM & Mean & SEM & Mean & SEM & Mean & SEM & Mean & SEM & \\
\hline Cu,Zn SOD (immunoreactivity score) & $3.38^{\mathrm{c}}$ & 0.26 & $1.88^{\mathrm{b}}$ & 0.23 & $2 \cdot 25^{\mathrm{b}}$ & 0.16 & $3 \cdot 38^{\mathrm{c}}$ & 0.26 & $0.75^{\mathrm{a}}$ & 0.25 & $1.00^{\mathrm{a}}$ & 0.27 & 0.0000 \\
\hline Mn SOD (immunoreactivity score) & $1.63^{\mathrm{b}}$ & 0.26 & $0.13^{\mathrm{a}}$ & 0.13 & $2 \cdot 13^{\mathrm{b}}$ & 0.44 & $1.63^{\mathrm{b}}$ & 0.32 & $0.38^{\mathrm{a}}$ & 0.26 & $2 \cdot 25^{\mathrm{b}}$ & 0.31 & 0.0002 \\
\hline CAT (immunoreactivity score) & $3 \cdot 13^{\mathrm{a}}$ & 0.30 & $3.38^{b, c}$ & 0.26 & $3.50^{\mathrm{b}, \mathrm{c}}$ & 0.19 & $1 \cdot 88^{\mathrm{b}}$ & 0.44 & $3.63^{b, c}$ & $0 \cdot 18$ & $4 \cdot 13^{\mathrm{C}}$ & 0.23 & 0.0030 \\
\hline GR (immunoreactivity score) & $0.50^{\mathrm{a}}$ & 0.19 & $2 \cdot 88^{\mathrm{C}}$ & 0.30 & $1.50^{\mathrm{b}}$ & 0.33 & $0.50^{\mathrm{a}}$ & 0.19 & $3.38^{\mathrm{c}}$ & $0 \cdot 26$ & $1.38^{\mathrm{b}}$ & 0.26 & 0.0000 \\
\hline GPx (immunoreactivity score) & $0.50^{\mathrm{a}}$ & 0.19 & $0.88^{\mathrm{a}}$ & 0.35 & $0.63^{a}$ & 0.26 & $0.88^{a}$ & 0.30 & $2 \cdot 13^{\mathrm{b}}$ & 0.30 & $1.25^{\mathrm{a}}$ & 0.25 & 0.0126 \\
\hline Nrf-2 (immunoreactivity score) & $9 \cdot 75^{\mathrm{a}}$ & 1.93 & $70 \cdot 75^{\mathrm{c}}$ & $2 \cdot 06$ & $9 \cdot 38^{\mathrm{a}}$ & $2 \cdot 20$ & $8 \cdot 75^{\mathrm{a}}$ & $2 \cdot 25$ & $7 \cdot 75^{\mathrm{a}}$ & 1.53 & $25 \cdot 00^{b}$ & $2 \cdot 58$ & 0.0000 \\
\hline COX-2 (immunoreactivity score) & $1 \cdot 14^{a}$ & 0.24 & $1.00^{\mathrm{a}}$ & 0.27 & $1 \cdot 25^{a}$ & 0.25 & $0.88^{\mathrm{a}}$ & 0.23 & $0.63^{\mathrm{a}}$ & 0.26 & $0.75^{a}$ & 0.25 & 0.4837 \\
\hline iNOS (immunoreactivity score) & $1.00^{\mathrm{a}}$ & 0.27 & $1.63^{a, b, c}$ & 0.18 & $2.00^{c}$ & 0.33 & $1 \cdot 13^{a, b}$ & 0.30 & $1.88^{\mathrm{b}, \mathrm{c}}$ & 0.30 & $1.38^{\mathrm{a}, \mathrm{b}, \mathrm{c}}$ & 0.38 & 0.1845 \\
\hline
\end{tabular}

a,b,c Mean values with unlike superscript letters were significantly different between samples analysed by Tukey's test $(P<0.05)$.

EWS: 475\%, ERS: $200 \%$; distal EWS: 573\%, ERS: 63\% (P<0.0001)). This suggests that sorghum diets might enhance the GSH reduction capacity from GSSG in colonic mucosa by inducing GR up-regulation.

These results demonstrated that a better AO protection state would be present in the colon after consumption of sorghum diets. The $N r f-2$ AO response element signalling pathway is important to AO enzyme expression. To determine whether sorghum diets elicit their $\mathrm{AO}$ effects by regulating $\mathrm{Nrf}-2$, we also investigated cytosolic and nuclear $\mathrm{Nrf}-2$ immunolocalisation in proximal and distal colonic sections by immunocytochemistry analysis (Table 3). An intense positive $N r f-2$ staining along the colonic axis of the crypts in the cytoplasm and nuclei of the epithelial cells affecting mainly the middle and luminal crypt compartments has been shown in slices from rats fed both sorghum diets. The number of $N r f$-2-positive nuclei significantly increased with respect to $\mathrm{C}(P<0.0001)$ in the proximal colon for EWS-fed rats and distal colon for ERS-fed rats. However, C rats showed a weak and diffuse cytosolic $N r f-2$ staining distributed on the top of crypt cells. These results confirm that sorghum diets enhance $N r f-2$ nuclear translocation, which promotes the transcription of detoxifying or AO enzymes.

On the other hand, a similar COX-2 and iNOS immunostaining pattern was observed in all the groups (Kruskal-Wallis $P>0.05$ ) (Table 3). The immunolocalisation of $C O X-2$ and $i N O S$ enzymes showed very weak staining along the colonic axis of the crypts in the cytoplasm of the epithelial cells of the basal, the middle and the luminal crypt compartments. Similarly, Ritchie et $a l .{ }^{(47)}$ did not observe extensive inflammatory cell infiltration or fold changes in relative expression of COX-2, IL12b and ILC in DSS-induced colitis in rats fed bran sorghum diets.

The intestinal epithelial barrier integrity depends on a delicate balance between cellular proliferation and apoptosis. In the present work, the PCNA assay was used to quantify the colonocyte proliferation and the apoptotic process was assessed by TUNEL staining. In all animals, PCNA-labelled nuclei were typically located in the lower half of the crypts, which is the zone of proliferating cells, whereas the apoptotic bodies were typically located at the top of the crypts of the colonic epithelium (Fig. 1). A differential response to consumption of ERS or EWS has been found between proximal and distal colon. Microscopic examination of the colonic sections clearly showed a decreased level (23\%; $P<0.0001)$ of PCNA-positive cells in proximal mucosa of rat fed ERS (PCNA LI: 35.69 (SEM 1.68) v. 46.07 (SEM 3.17)\%) but did not significantly affect the TUNEL-positive cell $(P>0.05)$. As a consequence, ERS diet induced a modification in the crypt population with shorter crypts as shown in H\&E staining sections (Fig. 1, online Supplementary material). These results indicate that ERS elicits an antiproliferative effect but does not influence apoptosis in the proximal colonic mucosa. This decreased proliferation could enhance DNA repair. Positive effects of eating sorghum on cancer prevention have been documented ${ }^{(2,48)}$, with anthocyanins and ferulic acid being mainly involved in antiproliferative and AO effects. Thus, mainly the diet based in ERS may have protective effects against colorectal tumourigenesis in the proximal colon. These results could be associated with a reduction of oxidative environment of the proximal colonic mucosa through modulation of the AO system by ERS diet observed in this study. In this connection, several reports demonstrated that different plant polyphenolics could protect against pre-neoplastic conditions via induction of endogenous AO enzymes preventing oxidative stress ${ }^{(49)}$. No further differences were detected for the distal colon in ERS-fed rats. This could be because of the fact that during passage through the intestinal tract SCFA and polyphenolic metabolites from fermentation are absorbed by colonic mucosa and a less local effect may be found in the distal colon. In addition, sequential metabolism in the colon means that regions of proximal and distal colon are probably exposed to distinct profiles of active compounds from the diet. Thus, rats fed a diet containing AO grape fibre, another type of fibre plus polyphenols, attenuated the mitochondrial apoptotic pathway, which was correlated with an increase in the AO capacity of the fibre ${ }^{(50)}$, showing also an epithelial hypoplasia in the caecum and the distal colonic mucosa of Wistar rats ${ }^{(51)}$. On the other hand, consumption of EWS generated hyperproliferation in both proximal and distal colon, which could be associated with an increased risk of cancer, but also increased apoptosis of epithelial cells, indicating a faster renewal rate of the epithelium. Consequently, rats fed an EWS showed similar crypt depth as the $\mathrm{C}$ group $(P>0.05)$, without histological modifications in the mucosal 
(A) C EWS ERS
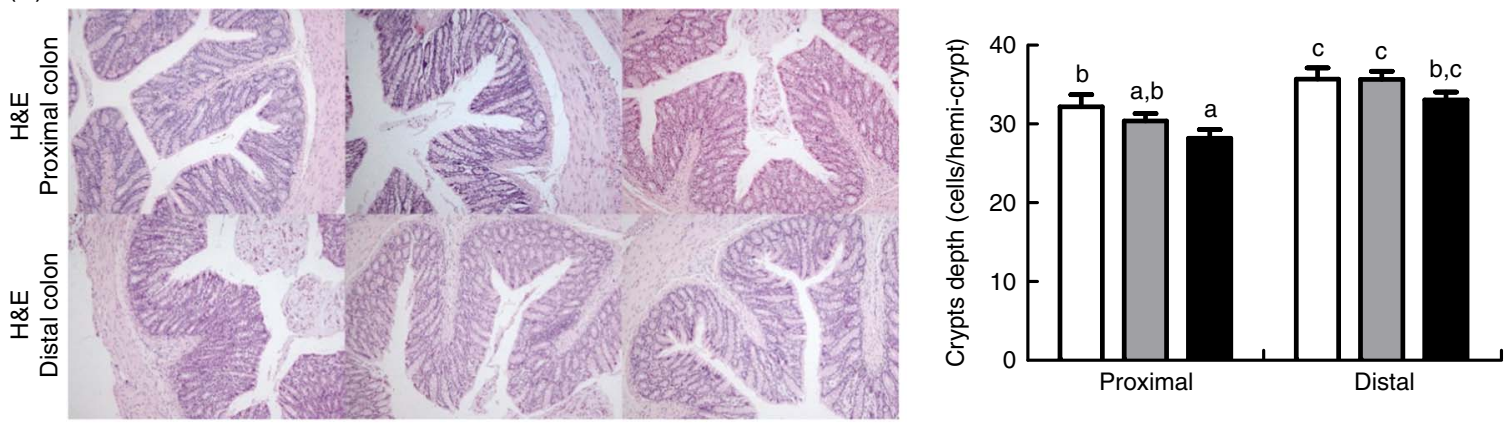

(B) C

EWS

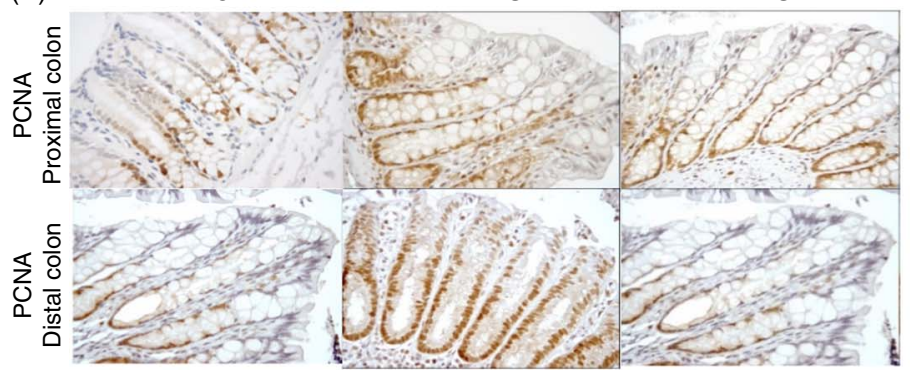

EWS

(C)

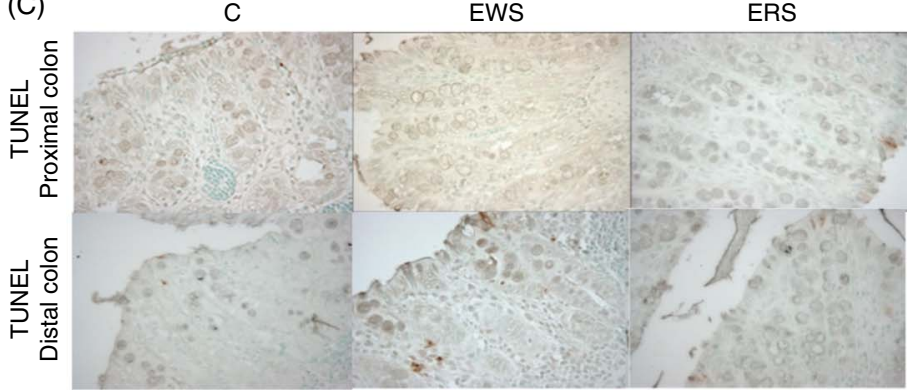

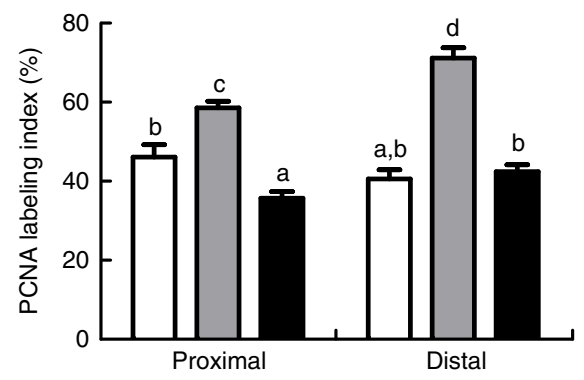

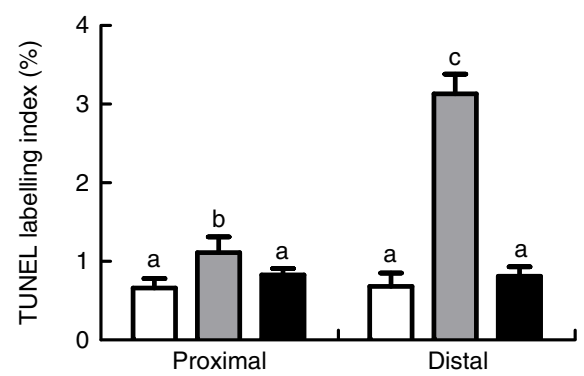

Fig. 1. Effects of extruded sorghum diets on crypts depth, cell proliferation and apoptosis in the rat proximal and distal colonic mucosa. (A) Representative haematoxylin-eosin (H\&E)-stained sections and the crypts depth measured as cells number per hemicrypt of the colon of rats fed with the control (C, $\square$ ), extruded white sorghum (EWS, $\square$ ) or extruded red sorghum (ERS, $\square$ ) diet (100x). (B) Representative photographs for immunohistochemical staining of proliferating cell nuclear antigen (PCNA) ( )-positive cells (400x magnification) and the PCNA labelling index (\%) in colon tissues from rats fed the control, EWS or ERS diet. (C) Colonic epithelial apoptosis as revealed by terminal deoxynucleotidyl transferase dUTP nick end labelling (TUNEL) assay of control, EWS- and ERS-fed rats (light microscope, $400 \times$ magnification) and quantification of apoptotic cells by TUNEL labelling index (\%). Values are means ( $n 8$ rats/group), with their standard errors represented by vertical bars. ${ }^{a, b, c, d}$ Mean values with unlike letters were significantly different (at least $P<0.05$ ) between groups.

architecture (Fig. 1). As the majority of apoptotic cells were localised in the place where apoptosis normally takes place, the increase could implicate that EWS ensures the re-establishment of homoeostasis of the colonic mucosa by removal of damaged cells, inducing a balance between proliferation and apoptosis. Torres et $a l .{ }^{(52)}$ observed significant changes in the small intestinal mucosa of broilers fed low-tannin sorghum diets, such as higher mitotic index and epithelial loss. The differential effect of sorghum fibres on colonocytes could be partially explained by taking into account the differences in fibre composition, particularly the fermentable components and their AO capacities. Ritchie et $a l .{ }^{(53)}$ demonstrated that the presence of bioactive compounds such as 3-deoxyanthocianins and condensed tannins derived from fermentation of sorghum brans may alter the luminal environment and microbial populations. These diets also can alter faecal SCFA concentrations, as butyrate, which would mediate an increase in proliferation, differentiation and apoptosis in the crypt in normal colonic epithelium $^{(54)}$.

Systemic effects of sorghum diets in growing Wistar rats (lipid profile and oxidative status) are shown in the online Supplementary material.

\section{Conclusions}

This study provides evidence of potential in vivo mechanisms for the protective and $\mathrm{AO}$ effects of diets rich in extruded sorghum. The consumption of extruded WG sorghum exerted physiological effects on the organism, both locally in the intestinal tract and systemically. Both EWS and ERS effectively showed a satiety effect reducing BW and decreasing caecal $\mathrm{pH}$ and caecal $\beta$-glucosidase and $\beta$-glucuronidase activities. In addition, ERS consumption increased sIgA, probably because of 
the higher content of polyphenols. Moreover, extruded sorghum exerted an additional favourable effect on the AO enzymatic system of both colon segments promoted by Nrf-2 nuclear translocation. A differential impact of the sorghum diets on the colonic mucosa has been demonstrated. Although ERS diet may have protective effects against colorectal cancer by decreasing proliferation, EWS induced hyperproliferation and also increased apoptosis of epithelial cells, ensuring the re-establishment of homoeostasis of the colonic mucosa. Although modest effects at the systemic level and lipid profile have been found, sorghum intake might be beneficial for preventing hypertriglyceridaemia. Taken together, these findings suggest that the consumption of extruded sorghum, mainly ERS, may prevent against certain diseases of the intestine by enhancing $\mathrm{AO}$ status and could be considered as a novel functional food for colon health.

\section{Acknowledgements}

The authors are thankful to the National Agency of Scientific and Technological Support (SECyT, PICT-1282) and the Universidad Nacional del Litoral (CAI + D 2011-PI-0367) for their financial support.

S. R. D. formulated the research questions and designed the entire study; E. E. L., R. E. C. and M. M. E. L.-O. carried out analytical determinations; Z. A. and A. W. designed diets and carried out animal study; M. M. E. L.-O., E. E. L. and S. R. D. analysed the data and wrote the article; M. M. E. L.-O. and S. R. D. had primary responsibility for final content; all authors read and approved the final manuscript.

None of the authors has any conflicts of interest to declare.

\section{Supplementary material}

For supplementary material/s referred to in this article, please visit https://doi.org/10.1017/S0007114517002513

\section{References}

1. Codex Alimentarius (CODEX) (2006) Request for comments on the draft action plan for the implementation of the Global Strategy on Diet, Physical Activity and Health, 2006/44.CAC CL, 3.

2. Awika JM \& Rooney LW (2004) Sorghum phytochemicals and their potential impact on human health. Phytochem $\mathbf{6 5}$, 1199-1221.

3. Miller HE, Rigelhof F, Marquart L, et al. (2000) Antioxidant content of whole grain breakfast cereals, fruits and vegetables. $J$ American Coll Nutr 19, 312S-319S.

4. Lee YM, Han SI, Song BC, et al. (2015) Bioactives in commonly consumed cereal grains: implications for oxidative stress and inflammation. I Med Food 18, 1179-1186.

5. Goñi I, Jiménez-Escrig A, Gudiel M, et al. (2005) Artichoke (Cynara scolymus L) modifies bacterial enzymatic activities and antioxidant status in rat cecum. Nutr Res 25, 607-615.

6. Kosmala M, Zduńczyk Z, Kołodziejczyk K, et al. (2014) Chemical composition of polyphenols extracted from strawberry pomace and their effect on physiological properties of diets supplemented with different types of dietary fibre in rats. EurJ Nutr 53, 521-532.
7. Manach C, Scalbert A, Morand C, et al. (2004) Polyphenols: food sources and bioavailability. Am J Clin Nutr 79, 727-747.

8. Kaczmarczyk MM, Miller MJ \& Freund GG (2012) The health benefits of dietary fiber: beyond the usual suspects of type 2 diabetes mellitus, cardiovascular disease and colon cancer. Metabolism 61, 1058-1066.

9. Van Hung P (2016) Phenolic compounds of cereals and their antioxidant capacity. Crit Rev Food Sci Nutr 56, 25-35.

10. Soong YY, Tan SP, Leong LP, et al. (2014) Total antioxidant capacity and starch digestibility of muffins baked with rice, wheat, oat, corn and barley flour. Food Chem 164, 462-469.

11. Dykes L \& Rooney LW (2006) Sorghum and millet phenols and antioxidants. J Cereal Sci 44, 236-251.

12. Hahn DH, Rooney LW \& Earp CF (1984) Tannins and phenols of sorghum. CFW 29, 776-779.

13. Hahn DH, Faubion JM \& Rooney LW (1983) Sorghum phenolic acids, their high performance liquid chromatography separation and their relation to fungal resistance. Cereal Chem 60, 255-259.

14. Yu J \& Tuinstra MR (2001) Genetic analysis of seedling growth under cold temperature stress in grain sorghum. Crop Sci 41, $1438-1443$

15. Stefoska-Needham A, Beck EJ, Johnson SK, et al. (2016) Flaked sorghum biscuits increase postprandial GLP-1 and GIP levels and extend subjective satiety in healthy subjects. Mol Nutr Food Res 60, 1118-1128.

16. Verbruggen MA, Beldman G, Voragen AGJ, et al. (1993) Water-unextractable cell wall material from sorghum: isolation and characterization. J Cereal Sci 17, 71-82.

17. Turner ND, Taddeo SS, McDonough CM, et al. (2010) Polyphenol-rich sorghum brands promote fecal water retention and alter short chain fatty acids in Sprague Dawley rats. Cereal Foods World 55, 4, Suppl., A72-A73.

18. Lemlioglu-Austin $\mathrm{D}$, Turner ND, McDonough CM, et al. (2012) Effects of sorghum [Sorghum bicolor (L.) Moench] crude extracts on starch digestibility, estimated glycemic index (EGI), and resistant starch (RS) contents of porridges. Molecules 17, 11124-11138.

19. Rastmanesh R (2011) High polyphenol, low probiotic diet for weight loss because of intestinal microbiota interaction. Chem Biol Interact 189, 1-8.

20. Llopart EE, Drago SR, De Greef DM, et al. (2014) Effects of extrusion conditions on physical and nutritional properties of extruded whole grain red sorghum (Sorghum spp). Int J Food Sci Nutr 65, 34-41.

21. Gu L, House SE, Rooney L, et al. (2007) Sorghum bran in the diet dose dependently increased the excretion of catechins and microbial-derived phenolic acids in female rats. $J$ Agric Food Chem 55, 5326-5334.

22. Salazar López N J, Loarca-Piña G, Campos-Vega R, et al. (2016) The extrusion process as an alternative for improving the biological potential of sorghum bran: phenolic compounds and antiradical and anti-inflammatory capacity. Evid Based Complement Alternat Med 2016, 8387975.

23. Djouzi Z \& Andlueux C (1997) Compared effects of three oligosaccharides on metabolism of intestinal microflora in rats inoculated with a human faecal flora. Br J Nutr 78, 313-324.

24. Folch J, Lees M \& Sloane Stanley GH (1957) A simple method for the isolation and purification of total lipides from animal tissues. J Biol Chem 226, 497-506.

25. Lowry O, Rosebrough N, Farr L, et al. (1951) Proteins measurement with the folin phenol reagent. J Biol Chem $\mathbf{1 9 3}$, $265-275$.

26. Qiu Y, Liu Q \& Beta T (2010) Antioxidant properties of commercial wild rice and analysis of soluble and insoluble phenolic acids. Food Chem 121, 140-147. 
27. Singleton VL, Orthofer R \& Lamuela-Raventos RM (1999) Analysis of total phenols and other oxidation substartes and antioxidants by means of Folin-Ciocalteu reagent. Methods Enz 299, 152-178.

28. Buege JA \& Aust SD (1978) Microsomal lipid peroxidation. Methods Enzymol 52, 302-310.

29. Aebi H (1984) Catalase in vitro. Methods Enzymol 105, 121-126.

30. Horn HD (1982) Glutathione reductase. In Methods of Enzimatic Analysis, pp. 258-265 [HU Bergmeyer, editor]. Weniheim: Verlag Chemie.

31. Paglia DE \& Valentine WN (1967) Studies on the quantitative and qualitative characterization of erythrocyte glutathione peroxidase. J Lab Clin Med 70, 158-169.

32. Hissin PJ \& Hilf R (1976) A fluorometric method for determination of oxidized and reduced glutathione in tissues. Anal Biochem 74, 214-226.

33. Gavrieli Y, Sherman Y \& Ben-Sasso SA (1992) Identification of programmed cell death in situ via specific labeling of nuclear DNA fragmentation. J Cell Biol 119, 493-501.

34. Albarracín M, Weisstaub AR, Zuleta Á, et al. (2014) Effects of extruded whole maize, polydextrose and cellulose as sources of fibre on calcium bioavailability and metabolic parameters of growing Wistar rats. Food Funct 5, 804-810.

35. Adam A, Levrat-Verny MA, López H, et al. (2001) Whole wheat and triticale flours with differing viscosities stimulate cecal fermentations and lower serum and hepatic lipids in rats. J Nutr 131, 1770-1776.

36. Adam A, Lopez HW, Leuillet M, et al. (2003) Whole wheat flour exerts cholesterol-lowering in rats in its native form and after use in bread-making. Food Chem 80, 337-344.

37. Topping DL \& Clifton PM (2001) Short-chain fatty acids and human colonic function: roles of resistant starch and nonstarch polysaccharides. Physiol Rev 81, 1031-1064.

38. Slavin J (2013) Fiber and prebiotics: mechanisms and health benefits. Nutrients 5, 1417-1435.

39. Delcour JA, Aman P, Courtin CM, et al. (2016) Prebiotics, fermentable dietary fiber, and health claims. Adv Nutr 7, 1-4.

40. Halliwell B, Rafter J \& Jenner A (2005) Health promotion by flavonoids, tocopherols, tocotrienols, and other phenols: direct or indirect effects? Antioxidant or not? Am J Clin Nutr 81, 268S-276S.

41. Shiau SY \& Chang GW (1983) Effects of dietary fiber on fecal mucinase and beta-glucuronidase activity in rats. J Nutr $\mathbf{1 1 3}$, 138-144.

42. Zdunczyk Z, Jankowski J, Mikulski D, et al. (2013) Gastrointestinal morphology and function in turkeys fed diets diluted with whole grain wheat. Poult Sci 92, 1799-1811.
43. Rowland IR (1988) Interactions of the gut microflora and the host in toxicology. Toxicol Pathol 16, 147-153.

44. Justil H, Arroyo J \& Valencia J (2010) Extracto etanólico de Baccharis genistelloides (carqueja) sobre el cáncer de colon inducido con 1, 2-dimetilhidrazina en ratas (Ethanolic extract of Baccharis genistelloides (carqueja) on colon cancer induced with 1,2-dimethylhydrazine in rats). Anales de la Facultad de Medicina 71, 88-96.

45. Dani C, Oliboni LS, Pasquali MA, et al. (2008) Intake of purple grape juice as a hepatoprotective agent in Wistar rats. $J$ Med Food 11, 127-132.

46. López-Oliva ME, Agis-Torres A, Goñi I, et al. (2010) Grape antioxidant dietary fibre reduced apoptosis and induced a pro-reducing shift in the glutathione redox state of the rat proximal colonic mucosa. Br J Nutr 103, 1110-1117.

47. Ritchie LE, Taddeo SS, Weeks BR, et al. (2017) Impact of novel sorghum bran diets on DSS-induced colitis. Nutrients 9, 330 .

48. Turner ND, Diaz A, Taddeo SS, et al. (2006) Bran from black or brown sorghum suppresses colon carcinogenesis. FASEB J 20, A599.

49. Rodríguez-Ramiro I, Ramos S, López-Oliva E, et al. (2011) Cocoa-rich diet prevents azoxymethane-induced colonic preneoplastic lesions in rats by restraining oxidative stress and cell proliferation and inducing apoptosis. Mol Nutr Food Res 55, 1895-1899.

50. López-Oliva ME, Pozuelo MJ, Rotger R, et al. (2013) Grape antioxidant dietary fibre prevents mitochondrial apoptotic pathways by enhancing $\mathrm{Bcl}-2$ and $\mathrm{Bcl}-\mathrm{x} \mathrm{L}$ expression and minimising oxidative stress in rat distal colonic mucosa. $\mathrm{Br} \mathrm{J}$ Nutr 109, 4-16.

51. López-Oliva ME, Agis-Torres A, García-Palencia $\mathrm{P}$, et al. (2006) Induction of epithelial hypoplasia in rat cecal and distal colonic mucosa by grape antioxidant dietary fiber. Nutr Res 26, 653-658.

52. Torres KAA, Pizauro JM, Soares CP, et al. (2013) Effects of corn replacement by sorghum in broiler diets on performance and intestinal mucosa integrity. Poult Sci $\mathbf{9 2}$, 1564-1571.

53. Ritchie LE, Sturino JM, Carroll RJ, et al. (2015) Polyphenol-rich sorghum brans alter colon microbiota and impact species diversity and species richness after multiple bouts of dextran sodium sulfate-induced colitis. FEMS Microbiol Ecol 91, fiv008.

54. Davidson MH \& McDonald A (1998) Fiber: forms and function. Nutr Res 18, 617-624. 